
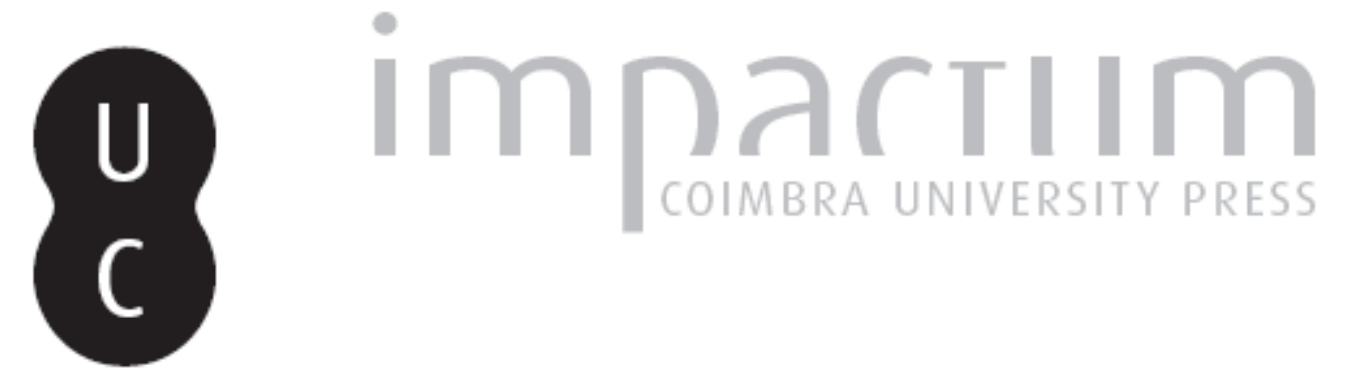

\title{
Os discrimes do tempo: reescrever o passado e imaginar o futuro em três romances italianos contemporâneos
}
Autor(es):
Bettini, Clelia
Publicado por: Faculdade de Letras da Universidade de Coimbra
URL
persistente:
URI:http://hdl.handle.net/10316.2/32290
DOI:
DOI:http://dx.doi.org/10.14195/0870-4112_10_8
Accessed : $\quad$ 26-Apr-2023 10:28:16

A navegação consulta e descarregamento dos títulos inseridos nas Bibliotecas Digitais UC Digitalis, UC Pombalina e UC Impactum, pressupõem a aceitação plena e sem reservas dos Termos e Condições de Uso destas Bibliotecas Digitais, disponíveis em https://digitalis.uc.pt/pt-pt/termos.

Conforme exposto nos referidos Termos e Condições de Uso, o descarregamento de títulos de acesso restrito requer uma licença válida de autorização devendo o utilizador aceder ao(s) documento(s) a partir de um endereço de IP da instituição detentora da supramencionada licença.

Ao utilizador é apenas permitido o descarregamento para uso pessoal, pelo que o emprego do(s) título(s) descarregado(s) para outro fim, designadamente comercial, carece de autorização do respetivo autor ou editor da obra.

Na medida em que todas as obras da UC Digitalis se encontram protegidas pelo Código do Direito de Autor e Direitos Conexos e demais legislação aplicável, toda a cópia, parcial ou total, deste documento, nos casos em que é legalmente admitida, deverá conter ou fazer-se acompanhar por este aviso.

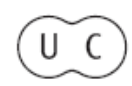



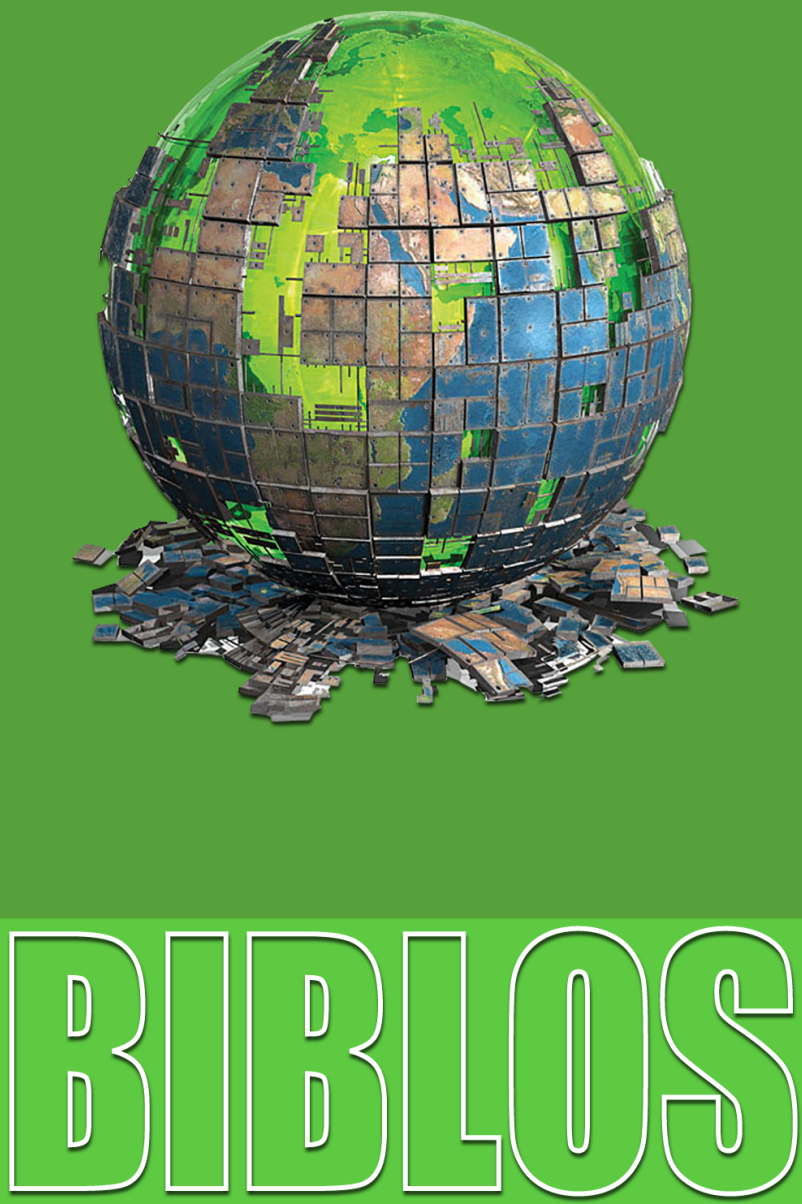

$\frac{\text { REVISTA DA FACULDADE DE LETRAS }}{\text { UNIVERSIDADE DE COIMBRA }}$ 
Biblos, n. s. X (2012) $\ldots-\ldots$

Clelia Bettini

Faculdade de Letras da Universidade de Coimbra

\section{OS DISCRIMES DO TEMPO \\ Reescrever o passado e imaginar o futuro em três romances italianos contemporâneos}

\section{Resumo}

A palavra CRISE procede da raiz KR-/SKR-, uma das mais fecundas raízes indo-europeias que deu os seus frutos em muitas das línguas modernas. Contém em si a ideia preciosa de juízo (gr. KRINOMAI), de limite que determina a escolha (lat. DISCRIMEN, ing. SHORE), da separação que indica o que é preciso salvar e o que se pode deitar fora (lat. EXCREMENTUM). Contudo, é central a noção de reflexão que subjaz no uso e abuso da palavra CRISE que se tem vindo a fazer. Está implícita uma dilatação do pensamento crítico, necessária numa fase histórica onde a sensação de viver uma emergência se tornou quotidiana. Assomam-se à janela do presente que vivemos o medo de um futuro demasiado opaco e a omnipresente nostalgia do passado, muitas vezes interligados numa mistificação utilitarista (Bauman: 2006).

A mais recente produção literária italiana propõe diversos instrumentos interpretativos da realidade, através da forma já demasiadas vezes declarada senão morta, ao menos moribunda, do romance. Alessandro Bertante imagina em Nina dei lupi (Marsilio, 2011) um futuro apocalíptico onde os últimos humanos voltam à dureza da montanha dos resistentes; Laura Pariani também regressa à montanha, em concreto ao Valle delle donne lupo, onde o movimento retrospectivo da lembrança leva a uma possível reconfiguração do tempo presente, através da convivência com recordos e fantasmas; e de fantasmas excelentes nos conta Emanuele Trevi em Qualcosa di scritto (Ponte alle Grazie, 2012), romance onde as figuras de Pierpaolo Pasolini e Laura Betti se tornam guias para o recente passado (os anos noventa) e o futuro incerto da cultura italiana. $\mathrm{O}$ espaço periférico dos vales e das montanhas do Piemonte, habitado por histórias de personagens desde sempre consideradas marginais uma menina, mulheres sós e independentes, loucos e loucas, lobos e lobas - e a centralidade da cidade de Roma, desassossegada pela alma do eterno diferente de Pasolini, que nos leva até à Grécia dos mistérios de Elêusis, tocam a sinfonia das angústias do início do século e da sua reiterada decadência. E pintam cenários interiores que merecem a pena de serem reflectidos, segredam respostas a quem for capaz de as ouvir, no alvoroço dos anos "em crise". 


\title{
Palavras-Chave: ...
}

\begin{abstract}
The word CRISIS derives from the root KR-/SKR-, one of the most proliferous Indo-European roots that has borne fruit in many modern languages. It contains the invaluable notion of judgement (Gr. KRINOMAI), of the boundaries that determine choice (Lat. DISCRIMEN, Eng. SHORE), of the line which separates what must be salvaged from what may be discarded (Lat. EXCREMENTUM). Nevertheless, the idea of reflection underlying the current use and over-use of the word CRISIS is of the utmost importance. It implies the broadening of critical thinking, which is necessary in a historical time where the feeling of living in a state of emergency has become a daily experience. The present is haunted by the fear of an opaque future and by the omnipresent nostalgia of the past, which are often intertwined in utilitarian mystification (Bauman: 2006).

The most recent Italian literary works bring forth several tools for interpreting reality via the novel, a form too often declared dead - or at least on its deathbed. In Nina dei lupi (Marsilio, 2011) Alessandro Bertante creates an apocalyptic future where the last remaining humans return to the hardship of the mountains; Laura Pariani also goes back to the mountains, more specifically to the Valle delle donne lupo, where the retrospective movement of remembrance leads to a possible reconfiguration of the present through the coexistence of memories and ghosts. In fact, in Qualcosa di scritto (Ponte alle Grazie, 2012) Emanuele Trevi presents us with a couple of fine ghosts, namely Pierpaolo Pasolini and Laura Betti, who become the guides to the recent past (the 1990's) and the uncertain future of Italian culture. Piedmont is a peripheral space composed of valleys and mountains and inhabited by the stories of characters considered marginal since ancient times - little girls, single and independent women, fools, wolves. Rome, on the other hand, is a central space haunted by the ever-different soul of Pasolini, who takes us back to Ancient Greece in the time of the Eleusinian Mysteries. These two spaces set the tone for the anxieties of the new century and its repeated decadence. Furthermore, they conjure up inner scenarios that are worth reflecting upon and that whisper answers to anyone capable of hearing them in the turmoil of the times of "crisis".
\end{abstract}

Keywords: ... 
Crise. O som estridente da velar e da líquida que se encontram sob um $i$ demasiado pequeno para suportar o seu peso, persegue-nos, segue-nos para toda a parte. É um som internacional, gritado, é o som do desespero e da retórica, da mais cínica e desapiedada publicidade. Mas o que significa verdadeiramente esta palavra? Como tantas outras vezes, a reflexão sobre a linguagem - a vertiginosa verticalidade das palavras - pode abrir à nossa frente a melhor via para nos acercarmos da literatura e da cultura actual. Vale a pena reflectir brevemente sobre a origem profunda do termo crise, que mergulha as suas raízes num tempo distante do nosso.

A palavra crise deriva directamente do latim CRISIS, por sua

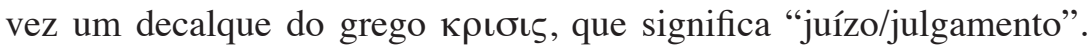

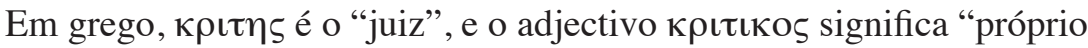

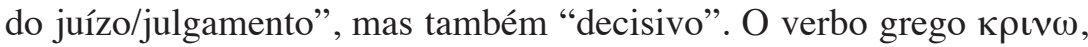
por sua vez, significava "julgar".

A raiz indo-europeia à qual crise pode ser reportada é KER- ou KRou SKR- (as vogais podiam mudar). Esta raiz dá origem a outras palavras que parecem não ter grande relação com a ideia de "juízo/julgamento"

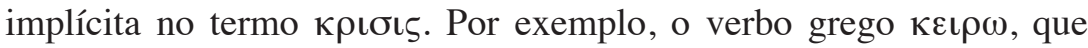
significa "cortar/tosquiar" ou o sânscrito KRNATI, que significa "matar", ou ainda o substantivo APASKARA, "excremento". Ainda em latim, as palavras CORIUM e CARO, que indicam, respectivamente, o couro e a carne, provêm também elas da raiz KR-, e até a palavra inglesa SHORE e o seu antecedente germânico SCHORE derivam de um verbo

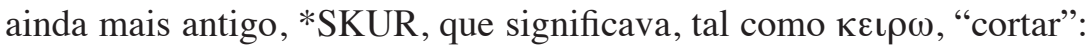
the shore de facto, não é senão a linha de demarcação que separa da terra as águas dos mares ou dos rios. Esta ideia de separação parece ser muito forte noutras palavras latinas que derivam da mesma raiz indo-europeia. É o caso de CERNO, CERNERE, “dividir, escolher”, e dos substantivos DISCRIMEN, -NIS "divisão, diversidade, diferença" e EXCREMENTUM, "folhelho", ou seja, o que resta quando se separa do trigo o grão utilizado para fazer a farinha. Todavia, também o alemão REIN, "puro", do gótico HREINN, deriva da mesma raiz, tal como a palavra RAIN que significa "margem, borda, limite".

$\mathrm{O}$ sentido mais genérico e primitivo associável à raiz KR- é o de cortar. Pensemos nas palavras latinas CORIUM, "pele, casca" e CARO (carne): a pele, o couro, é o que se pode cortar do corpo do animal, tal como a carne é um pedaço do corpo do animal que separamos do todo. 
$\mathrm{O}$ acto de cortar implica a ideia de separar, dividir. Também o termo EXCREMENTUM encerra em si a ideia de algo que foi separado e que, em seguida, se torna sobra, resíduo (desta ideia deriva o significado italiano de escremento). O mesmo é válido para o verbo CERNO, CERNERE, porque apenas se pode escolher após ter separado as coisas a seleccionar. E à ideia de escolha está fortemente ligada a de decisão, juízo/julgamento, que nos leva à origem da palavra grega крıбı૬ da qual partimos.

Detenhamo-nos aqui, por ora, no momento da escolha e sobre o movimento de análise crítica necessário para aí chegar. Detenhamo-nos neste limite, sobre a crista da montanha que é o nosso presente suspenso entre passado e futuro, na tentativa de dissipar as nuvens que ofuscam a visão do panorama lá em baixo, com o auxílio da literatura.

Há milénios que a literatura provém do humano em socorro do humano. Também na sua extrema simulação de ser inspirada por um deus, não é mais que um recurso para tranquilizar, para ajudar o homem a reflectir sobre si mesmo, para enfrentar os seus medos. E é por isso que faz sentido partir da literatura contemporânea para procurar compreender o tempo presente. Mover-nos-emos em três textos publicados entre 2011 e 2012, que apresentam características diversas entre si mas se colocam de pleno direito na "zona romance", superando as eventuais polémicas sobre o presumido desaparecimento da forma romance nos nossos dias: La valle delle donne lupo ( $O$ vale das mulheres lobo) de Laura Pariani, Nina dei lupi (Nina dos lobos) de Alessandro Bertante e Qualcosa di scritto (Alguma coisa escrita) de Emanuele Trevi. ${ }^{1}$

Laura Pariani é uma escritora dificilmente catalogável. Não é uma star, como tantos escritores de hoje. Talvez porque não seja uma escritora de hoje ou, pelo menos, do hoje mais à vista ou, melhor dizendo, dominante.

${ }^{1}$ Sobre a conexão entre contemporaneidade, imaginação e literatura, veja-se o amplo percurso de reflexão que Giulio Ferroni dedica ao tema, detendo-se longamente em autores-chave da segunda metade do século XX italiano, como Gadda, Morante ou Pasolini. G. Ferroni, “A literatura de 68. Imaginação e batalha cultural", in Literatura e Imaginação, coord. de Rita Marnoto, Série Leonardo, n. 3 , Coimbra: I. E. Ital. da FLUC, 2012. 
Numa nota final, a autora explica não apenas como nasceu La valle delle donne lupo mas como foi construído. É uma vantagem, uma oportunidade maravilhosa que, por vezes, os escritores concedem aos seus leitores e que por isso não deve ser descurada. Em primeiro ligar, o romance emerge de uma paixão da sua autora, a paixão pelo trabalho do historiador Cesare Bermani, figura de referência no estudo da tradição oral em Itália. Bermani encontra-se entre os fundadores do Istituto Ernesto de Martino e, entre os anos sessenta e setenta do século $\mathrm{XX}$, realizou um trabalho de pesquisa e gravação fundamental para a conservação do património dos cantares populares e sociais italianos, com Gianni Bosio e com a colaboração de Luciano Berio. ${ }^{2}$ A própria Pariani, na esteira dos estudos de Bermani, entre o final dos anos Setenta e o início dos anos Oitenta, recolheu diversas entrevistas a anciãs originárias do Alto Piemonte, sobre as tradições locais, as canções, as lendas da vida na montanha. Dessas entrevistas nasce não apenas a ideia de colocar no centro do romance Fenìsia, síntese e símbolo daquelas mulheres, mas a modalidade de alternar capítulos narrados em terceira pessoa, em que se narra o seu passado, e capítulos narrados em primeira pessoa, pela própria Fenìsia que, de qualquer forma, se mantém uma personagem inventada. Estamos perante uma narração verosímil, que retoma a práxis documental pela qual o nosso tempo é obcecado (a história verídica), num exercício de ficção que se torna símbolo de uma busca profunda da verdade. La valle delle donne lupo é a história de Fenìsia C., que fica sozinha no Paese Piccolo (Aldeia Pequena), um diminuto grupo de casas, separado do Paese Grande (Aldeia Grande) pelo espaço de um caminho impenetrável de montanha. Nascida em 1928, descende de uma família de sotterramorti (coveiros) e balenghe. Se sobre os primeiros não existem dúvidas, sendo as pessoas que "põem os mortos de baixo da terra", o termo balengo provoca imediatamente, no leitor que saiba italiano, aquela perturbação que torna as línguas ainda mais maravilhosas do que, por si só, já são. Trata-se de um termo dialectal difundido em todo o Norte de Itália para indicar alguém um pouco tolo, estranho, alguém que não tem os parafusos todos no sítio. Declinado no feminino, no dialecto do Alto Piemonte, pode ser sinónimo

${ }^{2}$ Veja-se a este respeito C. Bermani, Una storia cantata. 1962-1997. Trentacinque anni di vita del Nuovo Canzoniere Italiano, Milão: Jaca Book-Istituto Ernesto de Martino, 1997. 
de stria, bruxa, maga e curandeira. A avó de Fenìsia, Malvina, era uma destas mulheres, figuras temidas e desprezadas às quais, ainda assim, todos recorrem em tempos de necessidade. A palavra balengo pode derivar do verbo ballare, indicando alguém qua não caminha a direito ao longo da estrada, que ondula, que segue por vias travessas como um bêbado. Em suma, alguém que se desvia, que não segue o rebanho. Eis, pois, que as balenghe de Pariani são todas aquelas mulheres nãoalinhadas que reagem a seu modo, que não se conformam. As mulheres lobo, precisamente. Da casa de Fenìsia podem ver-se as duas últimas moradas possíveis: o cemitério, para quem segue as regras, e o prado das balenghe, terra dessacralizada onde há séculos são sepultadas as mulheres lobo.

Se Malvina, a avó da Fenìsia, é uma stria bela e boa, que conhece as ervas e as suas propriedades, a mãe Ghitìn é uma mulher frágil, atingida pela tuberculose, que é afastada pela comunidade quando Fenìsia é ainda criança. Sobre a sua sepultura paira o mistério, mas cada coisa parece apontar para o misterioso prado, acima do Paese Piccolo. E depois há Griselda, chamada a Grisa, a prima bela e selvagem que nem mesmo um pai violento consegue domar. Em criança, Grisa foge de casa para se juntar a uma alcateia. Quando regressa à comunidade nem sequer sabe falar e comporta-se como uma loba, para grande raiva dos seus familiares. A vingança dos "normais" será terrível: terminará no manicómio, durante anos, até que, graças à lei Basaglia, ${ }^{3}$ Fenìsia poderá ir buscá-la, após ter sofrido torturas infinitas em nome de um princípio de cura que, como se sabe, não era mais do que vigilância e punição da diferença que atemoriza. Através da vida de Fenìsia (1928-2007), Pariani conta a história de uma Itália da montanha que enfrentou com igual rigor a miséria do fascismo, o horror da guerra e as páginas dolorosas da Resistência, que por aquelas bandas travou algumas das suas batalhas mais duras. Descreve um mundo antigo, com os seus rituais, as suas crenças, onde ainda existe o capellaro ou seja um homem cujo ofício é comprar, por poucos cêntimos, os cabelos que as jovens põem de parte ao longo do ano ou as pesadas tranças que decidem vender. ${ }^{4}$ Onde a arte

\footnotetext{
${ }^{3}$ A lei 180 ou Lei Basaglia, do nome do médico que a redigiu, foi aprovada pelo Parlamento italiano em 1978 e estabeleceu a abolição dos hospitais psiquiátricos. Ainda está em vigor.

${ }^{4}$ L. Pariani, La valle delle donne lupo, Turim: Einaudi, 2012, p. 74.
} 
de ser a fisica (curandeira) é passada de mãe para filha, ou de avó para neta, como no caso de Malvina e de Fenìsia que, quando uma mulher em necessidade vem procurá-la, a faz sentar-se à mesa, porque «antes dos vaticínios, três plantas devem encontrar-se. De facto, colocava na mesa uma toalha branca - o cânhamo - depois o prato com a fogaça quente - o trigo - e uma garrafa de vinho - a videira»..$^{5}$ É um livro que narra um mundo desaparecido, mas não através da voz de quem o dominou, de quem dele detinha o uso e abuso exclusivo, mas através da voz de quem subsistia à margem, na tentativa desesperada de levar uma vida livre, numa luta perene contra as grades e as proibições impostas pelos "normais", por uma cruel maioria que, todavia, parece sempre ter precisado daquelas lobas. Não é por acaso que Pariani trabalha sobre a voz, sobre o modo com que faz falar a sua loba. A Fenìsia usa uma língua pessoal, um dialecto piemontês misturado com lombardo, depurado o suficiente para o tornar compreensível para o leitor que conhece o italiano standard, mas suficientemente híbrido para evocar a doce estranheza da falante. É uma língua originalíssima, uma escolha estilística de grande importância que denota a coragem de reflectir a fundo sobre a realidade. Mas porquê esta escolha, porquê escrever um romance assim em 2011? O que representa a voz de Fenìsia, o seu incessante recordar nesta extraordinária língua inventada?

Tudo é já acabado. Aquilo que por vezes poderia querer já não existe. As presenças, as vozes dos outros, o tinir dandandan dos chocalhos quando os rebanhos enxameavam os prados em redor. Tudo acabado. O bosque começa a tomar posse da estrada; a senhora deu-se conta enquanto subia?... Aquilo que procura não existe senão na memória. Tudo. O bom e o mau, que tornavam este lugar vivo.

Fenìsia tem consciência de ser uma sobrevivente, porque depositária da memória. Um universo antigo que encerrava em si, como a última matrioska, um passado que parecia eterno. Há uma sensação de dramática finitude no romance de Fenìsia, acentuado pelo silêncio a que a obriga a morte, quando já chegámos à última linha. E contudo trata-se de um fim aparente. Esta precede a narração mas, graças a um jogo de espelhos, materializa-se na soleira, apenas na conclusão, permitindo

\footnotetext{
${ }^{5} I b .$, p. 108.
} 
ao leitor experienciar aquele mundo e guardá-lo consigo, na sua memória activa.

Pariani atribui àquela Pariani que muitos anos antes entrevistara as mulheres do Alto Piemonte uma «síndrome antiquária que frequentemente atinge os jovens, quando se encontram perante uma cultura destinada a desaparecer». ${ }^{6}$ Mas talvez essa síndrome já não seja prerrogativa exclusiva dos jovens se, trinta anos depois, se encontra a escrever um livro como La valle delle donne lupo. A literatura, expressão possível daquilo que comummente definimos como cultura, é a sua vítima, e o texto literário parece fazer-se instrumento de resistência, peça de um mecanismo que é estratégia de permanência, através do papel activo das suas personagens, escolhidas entre aquelas figuras de tenaz marginalidade, de desvio vital, que a própria maioria que decretou o fim de uma época, retrospectivamente, sempre procurou aprisionar nos limites de uma entediante e cruel normalidade.

Passemos ao segundo romance objecto das nossas reflexões, Nina dei lupi de Alessandro Bertante. Continuamos entre as montanhas do Alto Piemonte, naquele arco alpino menos conhecido, distante dos fatos vistosos dos esquiadores e das colunas de SUV apetrechadíssimos que levam alegres famílias em férias sempre iguais. Estamos nos Alpes obscuros, que incutem temor e respeito, os mesmos onde Fenìsia viveu toda a vida. O romance de Bertante, todavia, não parte do pressuposto de documentar um passado em vias de extinção, mas de apresentar um possível cenário futuro. Insere-se de pleno direito no filão da literatura pós-apocalíptica, ou seja, aquela literatura que imagina o nosso mundo - o humano - após uma catástrofe que o devastou completamente. Um dos mais recentes exemplos do género é, talvez, The Road de Cormac McCarthy (2006), em que Pai e Filho percorrem o caminho da fuga em direcção ao desconhecido, numa América feroz pós-nuclear, entre os restos de um mundo industrial agora silenciado e definitivamente congelado nas recordações ferrugentas de um passado que jamais poderá regressar. Em Nina dei lupi, ao invés, imagina-se um mundo do qual o homem teve de se afastar e onde a Natureza voltou a ser protagonista e dona e senhora de cada coisa. Após um trágico acontecimento misteriosamente denominado Tramontana Negra, uma

${ }^{6}$ Ib.p. 241 (nota da autora). 
pequena comunidade em fuga da cidade, já presa de hordas desapiedadas e loucas, recolhe-se na montanha, numa aldeia chamada Piedimulo.

Piedimulo era uma aldeia cega, fechada sobre si mesma, adormecida no silêncio do espírito ancestral. Naquele vale nunca entrara o turismo, nem indústrias, nem actividades comerciais de qualquer tipo. Demasiado isolada, difícil de alcançar, escura e secular, que apenas os montanheses conhecem. ${ }^{\text {? }}$

O lugar que a pequena comunidade escolhe para continuar a viver é muito semelhante ao Paese Piccolo descrito por Pariani. Um lugar onde

apenas contava o presente e a realidade concreta dos factos: a benevolência das colheitas, a fadiga do trabalho, a intensidade do fogo, o frio e o calor, a chegada das chuvas e a força do vento. Os aldeãos não pensavam no futuro. Devia ainda algum tempo. ${ }^{8}$

No futuro hipotético imaginado por Bertante, os homens e mulheres que no nosso presente de crise tinham esquecido o universo ancestral de Fenìsia ou o observavam com mansa indiferença, dão por si a prestar contas a uma realidade onde é a Natureza que comanda. Um mundo que parecia perdido, por ironia da sorte, transforma-se na única esperança de sobrevivência à catástrofe.

Entre eles encontra-se Nina, uma menina às portas da puberdade que, após ter perdido os pais nos dias da Tramontana Negra, se refugiou em Piedimulo com os avós. A personagem de Nina representa a ingenuidade, a alma pura do humano que pode entrar em contacto com a Natureza poderosa e luxuriante que nasce do afastamento do humano, corrupto e violento, típico do nosso tempo. As crianças, figuras marginais num mundo de adulta obtusidade, tornam-se para Bertante criaturas capazes de aprender uma nova linguagem, necessária para restabelecer a comunicação perdida com a Natureza, agora tornada dona dos espaços abandonados pela autodestruição humana. $\mathrm{E}$ a única linguagem possível, segundo Bertante, é a linguagem antiga e mágica da montanha. Não se trata de feitiçarias imaginárias, mas de simbologias, crenças e mitos custodiados durante milénios pelas populações itálicas

\footnotetext{
${ }^{7}$ A. Bertante, Nina dei lupi, Veneza: Marsilio, p. 15.

${ }^{8} \mathrm{Ib} ., \mathrm{p} .12$.
} 
do arco alpino. A iniciação de Nina nesta nova gramática de viver ocorre através de outra personagem chave, a "bruxa" Diana.

Diana, nome que não por casualidade evoca a deusa romana da caça e dos bosques e que na Idade Média, com a afirmação do cristianismo, se torna muitas vezes uma bruxa ou um demónio, ${ }^{9}$ é símbolo de uma transformação necessária:

A desventura colhera-a de surpresa, como a todos. Quando começou, pensava que fosse uma crise momentânea, uma espécie de válvula de escape útil para limar os excessos, para poder depois recomeçar a viver como antes. No seu belo bairro residencial ninguém parecia preocupar-se verdadeiramente com os primeiros sinais de desequilíbrio. Habitavam em condomínios protegidos por vigilância armada, tinham dinheiro e conhecimento, pensavam estar a salvo de más surpresas. E, contudo, as manchas no céu também lhes eram visíveis, aqueles sinais sem sentido que todas as manhãs os esperavam do lado de lá das janelas, e não podiam existir distinções perante o horror. ${ }^{10}$

Antes da misteriosa catástrofe, Diana era uma mulher abastada, esposa de um jornalista, morto nos dias turbulentos da Tramontana Negra. Como outros, a mulher encontrou refúgio em Piedimulo, com o filho pequeno, Luca. E naquela aldeia montanhesa assume completamente o papel de bruxa, de masca como ainda hoje se diz no Piemonte. O passado feminino das criaturas marginais que encontrámos no centro do universo em vias de extinção descrito por Pariani, torna a habitar uma mulher proveniente de um mundo totalmente diferente, que nunca para si imaginara um tal destino. Diana é uma espécie de "Fenìsia de retorno" que desempenha um papel-chave no romance de Bertante.

${ }^{9}$ Pense-se, por exemplo, nas Janas da Sardenha, minúsculas criaturas encantadas, a meio caminho entre seres humanos e divinos, cujo nome deriva, com grande probabilidade, exactamente de $(D)$ ianas, com aférese do $d$ - inicial. Vestígios das Dianas medievais podem também ser encontrados na Catalunha e em Portugal. Segundo Leite de Vasconcelos, no início do século passado, persistia no Algarve o hábito de utilizar o termo Jam ou Jans para indicar mulheres a quem eram atribuídos poderes feiticeiros. O termo é também atestado na Farsa de Inês Pereira de Gil Vicente (1523). Veja-se a este respeito V.Alford - R. Gallop, "Traces of a Dianic Cult from Catalonia to Portugal”, in Folklore, Vol. 46, N. 4 (1935), pp. 350-361, em especial a p. 359.

$$
{ }^{10} \mathrm{Ib} \text {., p. } 37 .
$$


Desde os primeiros capítulos do romance, a vida da comunidade de refugiados em Piedimulo é perturbada pela chegada de uma horda de salteadores. Os recém-chegados trazem consigo morte, violência, pilhagem, abuso e prepotência. Representam a componente humana que conduziu à catástrofe e que, apesar dela, se obstina em repropor, exacerbadas, as mesmas dinâmicas que a determinaram. A pequena Nina foge para a Montanha negra, encontrando refúgio junto de Alessio, o Homem dos Lobos que há algum tempo atrás escolhera viver isolado, como os animais com os quais firmou uma espécie de pacto de irmandade. Nina comporta-se, então, como a Grisa de Pariani, escolhe aprender uma nova linguagem, um modo diferente de viver, indispensável para derrotar os próprios medos e inimigos, em íntimo contacto com a Natureza que se reapossou do espaço subtraído ao homem. Os lobos simbolizam esta Natureza, encarnam-na no seu uivar que assusta tanto os aldeãos obtusos de Pariani como os salteadores de Bertante. Diana, por sua vez, tal como Fenìsia, mantém o contacto com a comunidade, um espinho que tortura os seus algozes. É de imediato feita prisioneira, mas ninguém consegue domá-la, único ser humano que não se verga à violência, envolta no mistério das suas fórmulas mágicas:

Que língua falava a bruxa? As suas cantilenas assustavam-no de morte [Fosco, o chefe dos salteadores]. Lengalengas antigas e aterrorizadoras. Que raio de religião era? Fosco tirara-lhe o filho. Tinha posto o pequeno bastardo a trabalhar com as meninas. Era útil, um menino dócil. À bruxa, ao invés, não conseguia domá-la. Como era possível? Todos os seus inimigos tinham tombado, um atrás do outro. Bastava esperar o ponto de ruptura, todos têm o seu. Mas ela não, ela resistia como uma fera enjaulada. ${ }^{11}$

A linguagem antiga das bruxas da montanha, a magia arcaica da qual são depositárias, torna-se também em Bertante símbolo de resistência. Transforma-se num saber que se opõe à degradação fosca da violência do mundo contemporâneo. Um passado mítico, mais próximo da Natureza e que com ela partilha uma boa dose de mistério, reemerge como única arma possível para superar os dias escuros da Tramontana Negra.

\footnotetext{
${ }^{11} \mathrm{Ib} ., \mathrm{p} .122-123$.
} 
Os romances de Pariani e Bertante falam do tempo presente, um tempo de crise que atravessa uma fase de transição dolorosa e sombria. Parecem opor-lhe um movimento do pensamento que volta a reflectir sobre uma época que o precedeu e que assume contornos mágicos e lendários. Uma era que se torna exemplar, salvífica, porque animada por antigas divindades que, ainda que desapossadas por uma nova religião e reduzidas às fileiras dos demónios marginais, nos lugares mais remotos continuam a exercer uma parte das suas antigas prerrogativas, precisamente como as Dianas medievais. Crianças, bruxas, loucos, um homem anti-social que escolheu viver em estreita comunhão com o rigor da Natureza selvagem e no pleno respeito por ela. Eis os modelos que devem inspirar um novo curso da História, segundo estes dois escritores italianos. Não é por acaso que a personagem de Nina, no futuro imaginário de Bertante, «quando as lendas se uniram ao mito», ${ }^{12}$ se transforma numa figura com capacidades sobre-humanas, capaz de governar alcateias inteiras e falar com os animais e curar as doenças com a sábia utilização das mãos e das ervas, ídolo das crianças e dos adultos que voltaram a povoar a montanha.

Também em Qualcosa di scritto de Emanuele Trevi o pensamento se move dentro dos limites da lembrança de uma idade anterior de valor exemplar. O romance centra-se nas figuras de dois espectros que, no entanto, não são assustadores como os fantasmas costumam ser. Trata-se de Pier Paolo Pasolini e Laura Betti, actriz, cantora, musa, amiga e última sacerdotisa legítima do culto pasoliniano. Podemos dizer que é uma obra iridescente, dependendo da forma como se olha para ela; lembra um livro de memórias mas também um ensaio de crítica literária (sobre o romance de Pasolini publicado postumamente, Petróleo, onde vai buscar o próprio título), em suma alguma coisa escrita,$^{13}$ porque a literatura é literatura e a subdivisão em géneros lembra de perto, muitas vezes, o comportamento neurótico de quem precisa de endireitar continuamente os objectos que tem sobre a mesa para poder sentir-se tranquilo.

O coração do romance é, então, constituído por uma reflexão sobre Petróleo e sobre o universo dos últimos anos da vida de Laura Betti,

${ }^{12} \mathrm{Ib} ., \mathrm{p} .219$.

${ }^{13}$ Qualcosa di scritto é o título do Apontamento 37 de Petróleo, de Pier Paolo Pasolini. Cf. P.P. Pasolini, Petrolio, Turim: Einaudi, 1992. 
quando era directora do Fondo Pasolini, onde trabalhava o jovem Trevi, através da qual entramos em contacto com o espectro de Pier Paolo Pasolini. Trevi apresenta estas duas experiências como portas de acesso a uma verdadeira revelação, que «atravessa a alma como um relâmpago» ${ }^{14}$ e se cumpre simbolicamente na "peregrinação" final a Eleusi. O mecanismo típico dos cultos pagãos - que se baseiam inteiramente na revelação aos que depois se tornarão iniciados está, segundo Trevi, na base de Petróleo e de toda a arte (e, portanto, da vida) do último Pasolini. Seguramente este núcleo de pensamento é o fulcro do livro de Trevi, mas põe em movimento uma série de reflexões mais amplas. Em primeiro lugar, remete para os dois espectros, para as personagens de Pier Paolo Pasolini e Laura Betti - a Louca, como lhe chama Trevi, numa síntese irónica do seu carácter psicótico - iluminando-os de sentido. Após a morte de Pasolini, Laura Betti comporta-se como única destinatária da obra do grande poeta, a única capaz de a compreender verdadeiramente pois para si fora escrita. É a última dos iniciados, a última a ter assistido ao ritual pagão, depositária de um saber que depois dela se perderá, não porque tenha sido a eleita mas simplesmente porque as coisas, no fim, aconteceram assim. Trevi amplifica o "pensamento dominante" de Betti e estende-o a um tipo de artista, ou talvez de intelectual - termo que não agrada a Trevi porque se tornou demasiado académico e tecnocrático - que hoje já não existe. Estas figuras corroídas pela honestidade, pela total incapacidade de cisão entre a vida e a própria arte, entre uma mão, um pé e um livro, uma pièce, um filme ou uma performance, rarefizeram-se, como o oxigénio, no nosso "deserto vermelho".

Importa acrescentar que, em 1992, quando Petróleo foi arrancado ao bem-aventurado sonho dos inéditos, livros destes não se fazem mais. São coisas que se tornaram incompreensíveis para a grande maioria do mundo. Alguma coisa mudou. ${ }^{15}$

Sim, alguma coisa mudou. Mas o quê?

Em primeiro lugar, a concepção moderna da literatura como forma insubstituível de conhecimento do mundo, e não como «um repertório de enredos bons para o cinema, muito menos um consumo destinado

${ }^{14}$ E. Trevi, Qualcosa di scritto, Roma: Ponte alle Grazie, 2012, p. 212.

${ }^{15} \mathrm{Ib}$. , p. 17. 
a uma ilusória elevação "espiritual", mas um desafio, um ultraje irremediável, o último aperto destinado a cravar a vida no coração da verdade. ${ }^{16}$

Pier Paolo Pasolini foi um dos últimos a pôr em prática este tipo de literatura. Obviamente, sem saber o que sucederia em seguida, sem suspeitar que, depois de séculos, aquele mecanismo imparável de superação permanente de si mesma, à qual todos estavam habituados, rapidamente abandonaria a literatura. Segundo Trevi, a mercantilização da literatura traduziu-se na sua integral transformação em produtos de narrativa que devem assemelhar-se o mais possível aos próprios leitores. Devem tranquilizá-los, mais que espantá-los, deslocá-los, e permitir a total identificação entre obra e fruidor. Tudo isto teria sido inconciliável com a vida de Pier Paolo Pasolini, porque

o seu método fundamental é exactamente o facto de ele, P.P.P., não se parecer com mais ninguém. Nem mesmo a História, esta infalível plaina, atenuou a anomalia em que consiste. [...] Se tivesse regressado à vida em 1992, juntamente com o manuscrito de Petróleo, teria sido sem dúvida idêntico àquele ressuscitado de que fala Dante no Convívio, que já não compreende a língua falada na sua cidade. ${ }^{17}$

Um estranho, uma figura incompreensível no tempo presente. Todavia, Pasolini era já uma figura marginal no seu tempo, tinha escolhido sê-lo. Na última fase da sua vida, em particular, mergulhava nas noites de Roma, cidade que em 1975, ano da sua morte, segundo Trevi já «se tornara irreconhecível, invadida e como que corroída por uma gélida estranheza». ${ }^{18}$ Portanto, Pasolini, como Fenìsia, como as bruxas, é um espinho também para a sua contemporaneidade e não apenas para o tempo presente, um corpo estranho que age dentro de uma sociedade em que não se reconhece. É já um espectro antes de morrer, tal como Laura Betti, a Louca, na sua totalizadora obesidade bulímica, envolvida na voz rouca e antipática que lhe conhecemos nos anos Oitenta do século passado.

Se as personagens de Pariani e Bertante podem ser interpretadas como Dianas de ascendência medieval, a época de contornos míticos

\footnotetext{
${ }^{16} \mathrm{Ib} ., \mathrm{p} .19$.

${ }^{17} \mathrm{Ib} ., \mathrm{p} .21$.

${ }^{18} \mathrm{Ib}$., p. 107.
} 
para a qual remete o romance de Trevi evoca uma espécie de idade dos heróis, como a imaginavam os antigos. Trata-se de uma época não muito remota, povoada por semideuses identificáveis com os protagonistas dos poemas homéricos do século $\mathrm{XX}$ que ainda agora terminou. Estes não andam armados com escudos e espadas poderosíssimas, não são dotados de extraordinários poderes envoltos na aura do sobrenatural, mas partilham com as divindades selvagens, de que falámos, a característica de serem figuras consideradas marginais no mundo ocidental em que vivemos.

Para continuar o paralelismo entre os três romances objecto desta análise, acrescentamos uma ulterior reflexão. Tal como lendo Pariani e Bertante se poderá pensar que, por vezes, a nostalgia daquele mundo arcaico em vias de extinção prevaleça sobre uma visão aberta ao futuro, pode ser-se induzido em erro por algumas afirmações de Trevi, até mesmo crer que veja no passado a única forma possível de resolver o futuro. Pense-se por exemplo quando, a propósito de um crítico francês que acompanha o autor, a Louca e uma outra personagem numa celebração pasoliniana na Grécia, nos anos Oitenta, diz: «Século XX, quanta falta me fazes! Chega a sentir-se nostalgia até por tipos como aquele tolo francês, comparados com o deserto de hoje.» ${ }^{19} \mathrm{Ou}$ ainda: «O século XX foi realmente um século maravilhoso. Considero uma fortuna ter lá estado, ter observado alguns dos seus últimos fogos.» ${ }^{20}$

$\mathrm{Na}$ realidade não se trata de nostalgia tout court, mas de uma experiência que talvez as gerações seguintes invejem mas que serve de motor essencial para a reacção, para colocar a máquina de novo em movimento. Trevi vê o século XX como um «momento histórico preciso, hoje tão distante dos nossos olhos que a sua luz é a do mito». ${ }^{21}$ Como os universos montanheses de Pariani e Bertante, o século XX, entendido como século artístico lato sensu, funciona como mito da idade dos heróis. No entanto, não basta imitá-los superficialmente, com aquele costume retro carregado de um muito vazio comprazimento com o qual hoje muitas vezes nos deparamos. Devem ser compreendidos na sua profunda plenitude. São portadores de esperança, abraçam-nos com a sua força, com a capacidade de serem únicos e contracorrente,

\footnotetext{
${ }^{19} \mathrm{Ib} ., \mathrm{p} .240$.

${ }^{20} \mathrm{Ib}$., p. 235.

${ }^{21} \mathrm{Ib} ., \mathrm{p} .87$.
} 
tal como Ulisses que se opõe a Poseidon ou se faz prender ao mastro principal para poder ouvir o dulcíssimo canto das sereias. E o mito torna-se necessário para superar um dos efeitos secundários mais insidiosos das épocas de crise: o medo do fim, que pode ser tão forte a ponto de paralisar todas as formas de vida.

Nestes textos literários, alguma coisa escrita que nos chega do ano passado, serpenteia uma sensação de medo latente. O medo da extinção de um património cultural no romance de Pariani, o medo pós-apocalíptico de um mundo ainda mais feroz que o nosso no texto de Bertante e o temor do fim de uma era da qual não resta mais que tímidos espectros. O medo é um sentimento estreitamente ligado à ideia de crise, não no sentido de decisão, é certo, mas de momento negativo, significado que a palavras assume nas línguas modernas num segundo momento.

Voltamos assim ao ponto em que momentaneamente nos detivemos para descansar, no início deste ensaio, na crista da montanha do nosso presente. Regressamos à linguagem e à verticalidade das palavras, para encontrar outros esclarecimentos de sentido. Como se chega ao deslizamento semântico que leva o significado da palavra crise de decisão a momento negativo? A resposta reside na experiência da medicina antiga. A palavra latina CRISIS era usada na medicina antiga para indicar um tipo particular de decisão: a fase decisiva da doença, aquela em que se decide a sorte da sua evolução. Normalmente esta fase corresponde a um momento doloroso e, naturalmente, perigoso. A ideia que os momentos negativos sejam reveladores é uma ideia interessante que se encontra em muitos campos do saber, não apenas na medicina. É nos momentos de crise que se vê verdadeiramente quanto valemos, o que somos capazes de fazer. E estas fases decisivas podem também transportar-nos a algo positivo, novo mas não necessariamente pior. Como na doença, podemos sofrer muito, mas vencer a noite.

Creio que os textos de que nos ocupámos, através da reconstrução literária de uma idade dos heróis que ainda nos é familiar, constituam uma ajuda preciosa. Nas conclusões a um seu recente ensaio sobre o tema do medo na nossa sociedade atacada pela globalização negativa, Zygmunt Bauman sugere algo semelhante..$^{22}$ Citando Pierre Bourdieu,

${ }^{22}$ Z. Bauman, Liquid fear, Cambridge: Polity Press, 2006 (aqui é citada a edição italiana, Z. Bauman, Paura liquida, Bari: Laterza, 2009). 
Bauman dirige-se a «quem tem a possibilidade de dedicar a própria vida ao estudo do mundo social» e, portanto, também a quem escreve e a quem estuda a literatura, afirmando que neste momento histórico invadido pelo que definiu como medo líquido «o seu dever [...] é, por outras palavras, o dever da esperança». ${ }^{23}$ Bauman reflecte em particular sobre o papel dos intelectuais e sobre o acordo implícito que, no século passado, tinham estabelecido com o povo (ambos os termos usados em sentido gramsciano). Aquele pacto, segundo o qual o teriam guiado em direcção

à história, à liberdade, à coragem da auto-afirmação, foi quebrado, ou melhor, revogado unilateralmente tal como fora proclamado no dealbar da era moderna. Os descendentes dos intelectuais de ontem - a actual elite do saber, que partilhou a "secessão dos satisfeitos" - movem-se num mundo muito diferente e privado de sobreposições com os muitos e diversos mundos nos quais se desmoronam e encarceram a vida e as perspectivas (ou antes, a ausência de perspectivas) do povo. ${ }^{24}$

Neste cenário de crise do papel daqueles que têm a "possibilidade de dedicar a própria vida ao estudo do mundo social", decididamente desligados, segundo Bauman (e anteriormente segundo Pasolini, em 1975) daquela que é a realidade da grande maioria da população desta terra, a esperança (e a meta-esperança, ou seja, a possibilidade de que exista uma esperança), torna-se fundamental. Bauman cita como extremamente actual um preceito fundamental de Adorno, segundo o qual «a função do pensamento crítico "não é conservar o passado mas realizar as suas esperanças"». ${ }^{25} \mathrm{O}$ pensamento crítico dos escritores cujas obras observámos de perto, a escolha que está por trás da construção dos seus universos de ficção, é exactamente esta: não conservar, nostálgicos, um passado extinto mas projectá-lo no futuro, através da realização das esperanças nele implícitas. Para quem decida, então, subir à crista da montanha do nosso presente, será sempre profícuo levar um livro na sacola, mesmo quando tudo indique que possa apenas ser um peso.

\footnotetext{
${ }^{23} I b .$, p. 218.

${ }^{24} I b .$, p. 219.

${ }^{25} \mathrm{Ib}$., p. 219.
} 